\title{
Elimination of Tellurium out of Molten Iron*
}

\author{
By Yoshimoto WANIBE,** Kohji SAWADA, *** Toshiharu FUJISAWA** \\ and Hiroshi SAKAO**
}

\begin{abstract}
Synopsis
Since the co-existence of a small amount of tellurium can be expected to improve the practical deoxidation of steel, three kinds of experimental examinations were carried out to eliminate the residual tellurium out of steel as the subsequent treatment. The results are

(1) Tellurium evaporates fairy fast out of the molten iron into $\mathrm{Ar}$ stream.

(2) Rare earth metal is the best substance to be added for the elimination of tellurium at a low oxygen potential of molten iron.

(3) $\mathrm{CaF}_{2}-\mathrm{CaCN}_{2}$ composite flux is also applicable, especially one with a composition ratio of $1: 1$ which has succeeded in reducing the residual concentration of tellurium to $\mathrm{rd}$. $20 \mathrm{ppm}$ (about $90 \%$ reduction performance) during 20 min treatment.
\end{abstract}

\section{Introduction}

In conventional steelmaking processes, aluminum is quite popular as a powerful deoxidizer of relatively low price. There, however, still remain some practical problems for the yield control of residual aluminum or for the estimation of deoxidation limit on the basis of equilibrium concept. One of the reasons is probably the emulsification of the deoxidation products as non-metallic inclusions.

Since a small addition of surface-active tellurium has been reported to facilitate the exclusion of alumina clusters out of molten steel, ${ }^{1)}$ the mechanism has been being intensively studied, ${ }^{2-4)}$ but the full details are not yet known. In our laboratory, the formation of the globular inclusions has been also observed in the presence of tellurium. At any rate, the tellurium addition can be anyhow expected to improve the usual aluminum deoxidation process and to reduce alumina inclusions in steel. Nevertheless, no practical performance has been reported yet. It seems to be due to negative factors, such as the high vapor pressure of tellurium, the apprehensive effect of the residual tellurium on steel properties, or the rising cost due to the extra procedures.

The present experimental research aims at searching the subsequent method, i.e., how to eliminate the residual tellurium out of the clean steel sufficiently killed through the above hypothetical treatment, apart from the foregoing complex problems, such as the mechanism etc. A criterion of low oxygen potential is conditioned for the present examination as well as for the studies on desulfurization.

\section{Experimental Apparatus and Method}

The following three kinds of experiments were carried out considering that tellurium is one of the chalcogen elements and very volatile at higher tem- peratures.

(1) The first experiment was intended to examine the evaporation of tellurium out of molten iron into an Ar stream (Experiment I).

(2) The next to investigate the applicabilities of various conventional desulfurizers for the present purpose (Experiment II).

(3) The last to test the practicability of composite flux mixture of $\mathrm{CaF}_{2}$ and $\mathrm{CaCN}_{2}$ which was selected on the basis of the second experimental results (Experiment III).

\section{Experimental Apparatus}

Induction heating was supplied with a $15 \mathrm{~kW}$ mercury gap spark type high frequency wave generator. The temperature was measured with an optical pyrometer. The crucibles used were mainly of magnesia $\left(50^{\phi} \times 40^{\phi} \times 100 \mathrm{~mm}\right)$, partly of alumina $\left(42^{\phi} \times 38^{\phi} \times 50 \mathrm{~mm}\right)$. An alumina gas inlet tube with about $6 \mathrm{~mm}$ inner diameter was furnished above the crucible along the central axis, and the lower end was adjusted to be $55 \sim 60 \mathrm{~mm}$ apart from the melt surface.

\section{Experimental Method}

About $400 \mathrm{~g}$ of electrolytic iron was melted in the magnesia crucible under Ar atmosphere (about $200 \mathrm{~g}$ of iron in the alumina crucible), and was reduced in about $1 \mathrm{hr}$ to $40 \sim 50 \mathrm{ppm} \underline{\mathrm{O}}$ with a $\mathrm{H}_{2}-\mathrm{Ar}$ mixture. Again under about $1 \mathrm{l} / \mathrm{min}$ of Ar stream, a suitable amount of tellurium glanular (99.99\% purity) was added at $1600^{\circ} \mathrm{C}$ so as to be a tellurium content level of 0.02 or $0.04 \mathrm{wt} \%$. After that, the melt sample was sucked at regular time intervals with a $3 \mathrm{~mm}$ I.D. silica tube (Experiment I). In Experiments II and III, the substance to be tested was further added 5 min later and the melt was sampled at given time intervals for $20 \mathrm{~min}$. The $20 \mathrm{~min}$ limit criterion was used because too long processing was considered to be practically meaningless.

Tellurium in the sucked samples was analyzed by means of the thio-urea absorption spectrophotometric method, oxygen and carbon by the coulometric titration method and nitrogen by the thermal conduction method.

\section{Experimental Results}

1. Evaporation of Tellurium (Experiment I)

Figures 1 and 2 show the time-dependent changes

* Originally published in Tetsu-to-Hagané, 66 (1980), 1468, in Japanese. English version received July 18 , 1980.

** Faculty of Engineering, Nagoya University, Furo-cho, Chikusa-ku, Nagoya 464.

*** Formerly Faculty of Engineering, Nagoya University. Now at Nanzan High School, Gokenya, Showa-ku, Nagoya 466. 
of tellurium and oxygen contents in the molten iron to which only tellurium has been added, respectively. The evaporation is quite effective in the elimination of tellurium from the molten ferroalloy, in spite of some distinctions between the experimental conditions, such as the purified or the crued argon and the different crucibles used. A ratio

$$
\eta_{\mathrm{Te}}(t)=\frac{[\mathrm{Te}]_{t=0}-[\mathrm{Te}]_{t}}{[\mathrm{Te}]_{t=0}} \times 100
$$

is now introduced to appraise the extent of the elimination performed during the treatment of $t \mathrm{~min}$, where [Te] is the concentration of tellurium in molten iron. Assumed that $20 \mathrm{~min}$ is the practically possible duration for the treatment, then the removability of about $40 \sim 50 \%$ can be performed under this experimental condition.

The time-dependent behavior of oxygen is the almost same as that in molten electrolytic iron under the same condition.

\section{Applicabilities of Conventional Desulfurizers (Experi- ment II)}

The above Experiment I have shown that only the evaporation can perform the elimination of tellurium

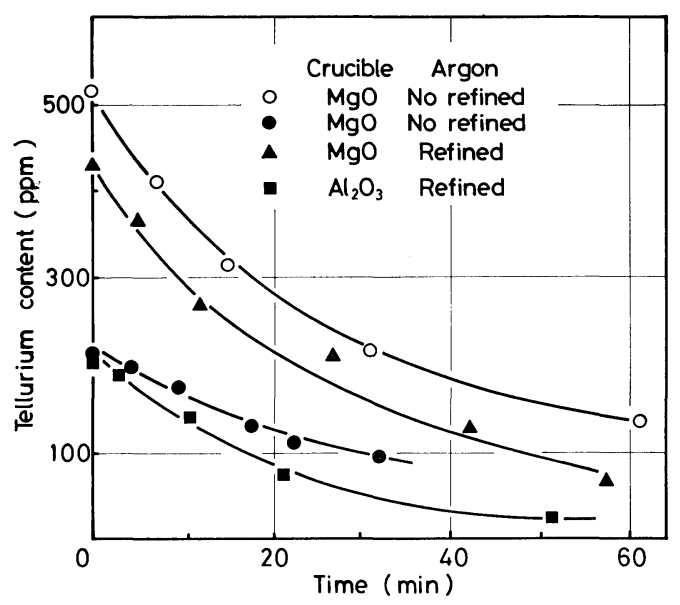

Fig. 1. Time-dependency of tellurium content under the Ar stream of $1 \mathrm{l} / \mathrm{min}$ at $1600^{\circ} \mathrm{C}$.

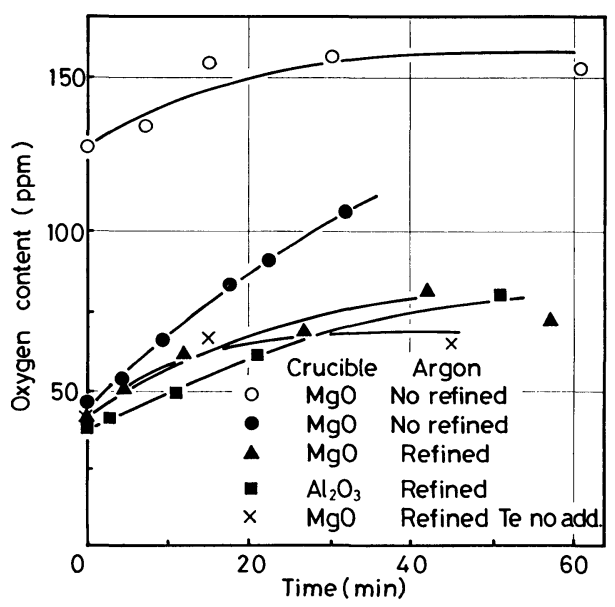

Fig. 2. Time-dependency of oxygen content in the case shown in Fig. 1. to a certain extent. For further complete performance, various conventional desulfurizers were examined in the applicability on the basis of tellurium belonging to the same group as sulfur in the periodical table. The experimental conditions, such as the tested materials, the added amounts, etc., are summarized in Table 1. Since all the reactions concerned are not yet known, the amount to be added cannot be definitely determined. So the stoichiometric equivalent amount was estimated on a simple assumption that metallic elements $X$ in desulfurizers become $X \mathrm{Te}$ or $X_{2} \mathrm{Te}$ with tellurium in molten iron through the reactions conceived with reference to the results of desulfurization experiments. Such an amount hereafter called " additive equivalence", was used as a quantitative criterion for addition. Composite materials were mixed up before the usage.

Figures 3 and 4 show the time-dependent changes in the concentrations of tellurium and oxygen after the addition of the materials shown in Table 1, respectively. From Fig. 3, the removabilities were calculated to be $66 \%$ for rare earth metal, and $62 \%$ $\mathrm{CaF}_{2}$ under the treatment limit of $20 \mathrm{~min}$. Then, $\mathrm{CaO}+\mathrm{CaF}_{2}, \mathrm{Al}, \mathrm{CaC}_{2}$ and $\mathrm{NaOH}$ follows on in order. According to Fig. 4, there are REM and $\mathrm{CaCN}_{2}$ which keep the molten iron at a low oxygen potential level during the treatment.

3. Practicability of the Flux Composed of $\mathrm{CaF}_{2}$ and $\mathrm{CaCN}_{2}$ (Experiment III)

The present purpose (of eliminating the residual tellurium out of killed molten iron without increasing oxygen content) requires the added materials (a) to

Table 1. Conditions used for the addition of various substances.

\begin{tabular}{|c|c|c|c|}
\hline No. & Substance & $\underset{(\mathrm{g})}{\text { Amount }}$ & $\begin{array}{l}\text { Initial Te } \\
\text { content } \\
(\%)\end{array}$ \\
\hline 1 & $\mathrm{Na}_{2} \mathrm{CO}_{3}$ (coarse powder) & 0.211 & 0.035 \\
\hline 2 & $\mathrm{CaCN}_{2}$ (fine powder) & 0.176 & 0.039 \\
\hline 3 & $\mathrm{CaC}_{2}$ (granule) & 0.132 & 0.037 \\
\hline 4 & $\begin{array}{l}\mathrm{MgO} \text { (fine powder) } \\
+ \\
\text { Al }\end{array}$ & $\begin{array}{l}0.071 \\
0.095\end{array}$ & 0.031 \\
\hline 5 & $\mathrm{CaF}_{2}$ (fine powder) & 0.156 & 0.039 \\
\hline 6 & $\begin{array}{l}\mathrm{CaO} \text { (coarse powder) } \\
+ \\
\mathrm{CaF}_{2} \text { (fine powder) }\end{array}$ & $\begin{array}{l}0.035 \\
0.136\end{array}$ & 0.039 \\
\hline 7 & $\mathrm{Al}$ (granule) & 0.048 & 0.030 \\
\hline 8 & $\begin{array}{c}\mathrm{MnO}_{2} \text { (coarse powder) } \\
\stackrel{+}{\mathrm{Al}} \text { (granule) }\end{array}$ & $\begin{array}{l}0.172 \\
0.075\end{array}$ & 0.033 \\
\hline 9 & REM (granule) & 0.310 & 0.044 \\
\hline 10 & $\mathrm{NaOH}$ (granule) & 0.226 & 0.031 \\
\hline
\end{tabular}

* Stoichiometrically equivalent to purging away the tellurium added according to the reactions assumed to be similar to those for desulfuration. 


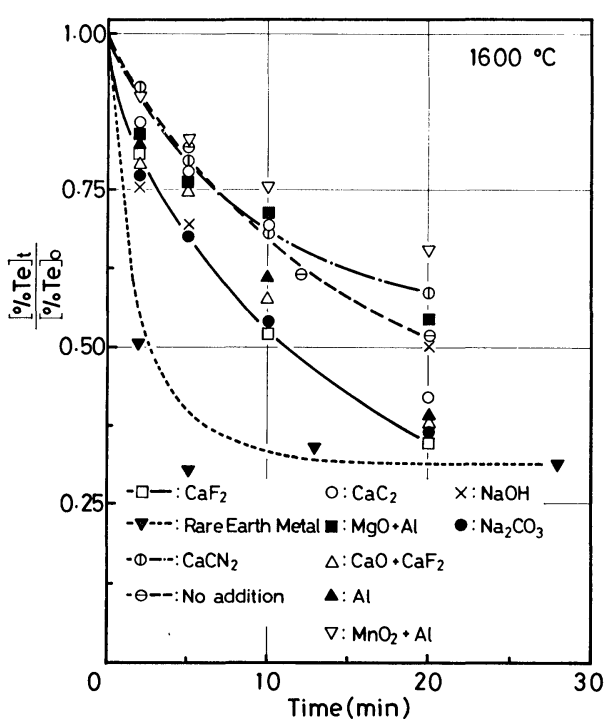

Fig. 3. Effect of the substances added on the removability of tellurium out of the melt.

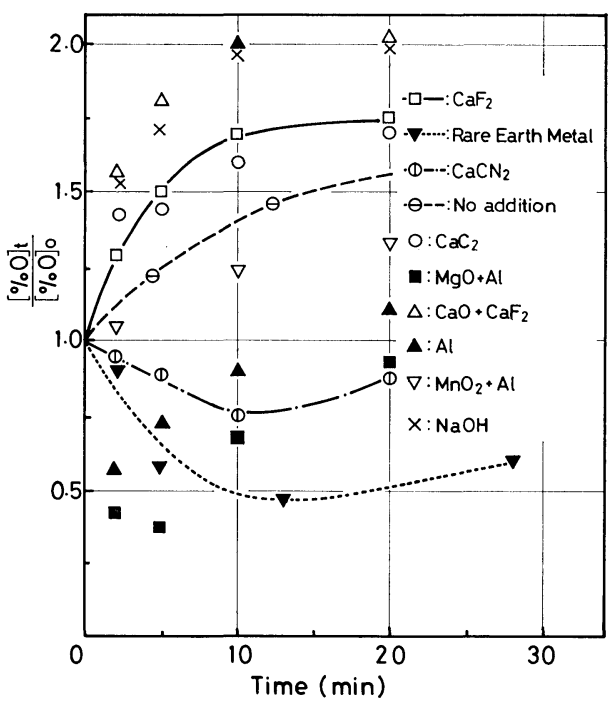

Fig. 4. Behavior of oxygen content in the case shown in Fig. 3.

have a powerful purging action and (b) to keep a low potential level of oxygen. According to the results of Experiment II described in the above section, REM is the best for this purpose, but expensive. Therefore, a trial examination was carried out in details on the practicability of the flux composed of $\mathrm{CaF}_{2}$ and $\mathrm{CaCN}_{2}$, on account of the former satisfying the condition (a) and the latter contenting the restriction (b).

\section{Amount and Composition of the $\mathrm{CaF}_{2}-\mathrm{CaCN}_{2} \mathrm{Com}$ -} posite Flux

Figures 5 and 6 show the experimental results carried out in the initial tellurium contents of 300 $400 \mathrm{ppm}$ with varying the amount and the composition of the composite flux. In the case of an additive equivalence shown in Fig. 5, the composition made no obvious differences between the results obtained, but did in the case of 4 times additive equivalence as shown in Fig. 6. Hence, the removability of tellurium eliminated during $20 \mathrm{~min}$ since the addition, was

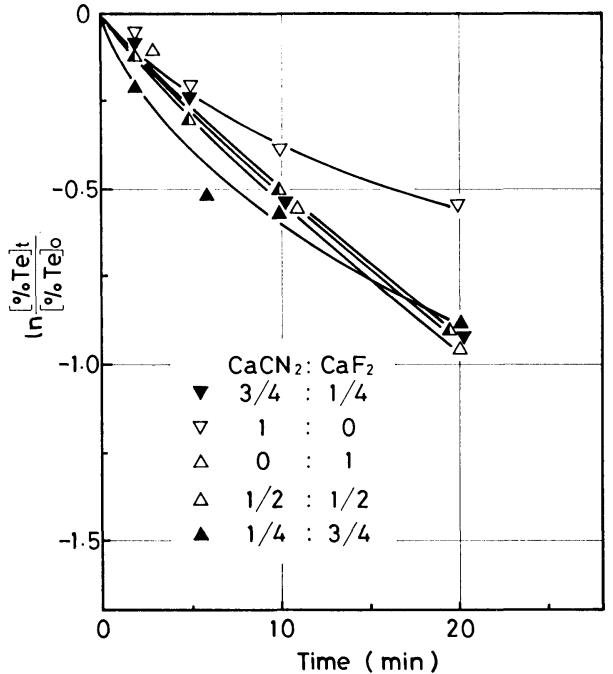

Fig. 5. Effect of the composition of $\mathrm{CaCN}_{2}-\mathrm{CaF}_{2}$ flux on the removal of tellurium in the case of 1 equivalent amount of addition.

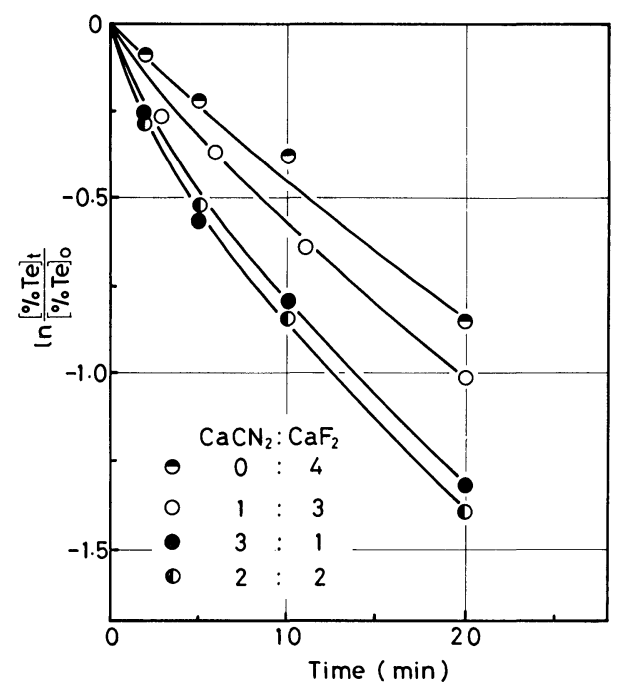

Fig. 6. Effect of the composition of $\mathrm{CaCN}_{2}-\mathrm{CaF}_{2}$ flux on the removal of tellurium in the case of 4 equivalent amount of addition.

calculated and shown against the composition of the mixture in Fig. 7. According to this figure, the best mixing ratio of $\mathrm{CaF}_{2}$ to $\mathrm{CaCN}_{2}$ seems to be about $1: 1$ for 4 times equivalent addition, then $1: 3$ and 3: 1 follows on in order.

Under the attention of the best flux composition (1:1), the further experimentation was repeated with varying the additive amount and the initial tellurium content. The results are summarized in Fig. 8 showing the elimination extent of tellurium performed during 20 min treatment against the amount of the added flux per $1 \mathrm{~g}$ tellurium initially dissolved. An initial tellurium content of $200 \mathrm{ppm}$ has been reduced to about $20 \mathrm{ppm}$, which is a $90 \%$ performance of the elimination.

\section{Time-dependent Concentrations of Oxygen, Carbon and Nitrogen Dissolved in Molten Iron}

Figures 9 and 10 show the changes in the oxygen and the carbon contents in the molten iron during the purging treatment of the composite flux, respec- 


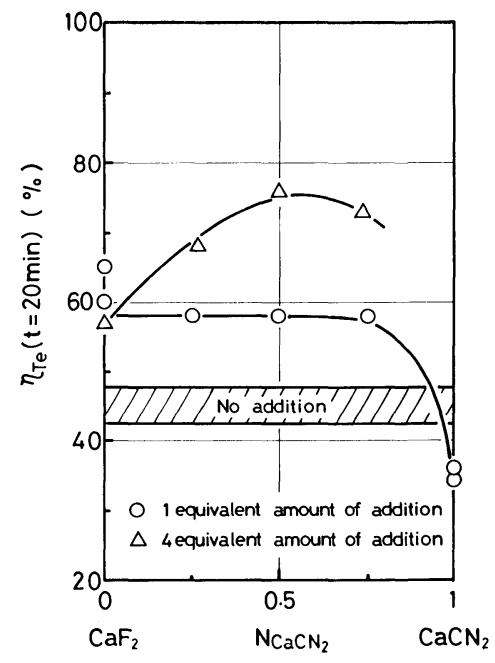

Fig. 7. Removability of tellurium dependent upon the composition of $\mathrm{CaF}_{2}-\mathrm{CaCN}_{2}$ flux.

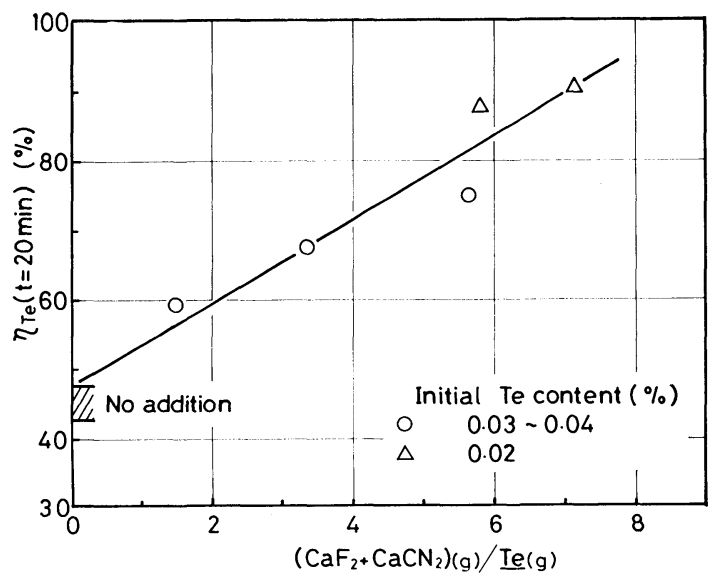

Fig. 8. Effect of the flux amount on the removability of tellurium in the case of the $\mathrm{CaF}_{2}-\mathrm{CaCN}_{2}$ mixture with the composition ratio of $1: 1$.

tively. The oxygen content remains being an almost constant level with no increase. The carbon content increases temporary after the flux addition, but decreases gradually with elapsing time. The nitrogen contents analyzed are 50 and $60 \mathrm{ppm}$ before and after the treatment, respectively, with being only $10 \mathrm{ppm}$ different. It is, therefore, safe to say that the composite flux affects little the concentrations of oxygen, carbon and nitrogen in molten iron.

\section{Formed Slag}

The addition of pure $\mathrm{CaCN}_{2}$ or the composites mixed in the higher ratio has formed a little amount of solid slag on some local parts of the molten iron surface. According to the qualitative analysis of the slag with an I.M.A., calcium and carbon have been detected and tellurium can be afforded proof of existence. For the usage of pure $\mathrm{CaF}_{2}$ or the mixtures with the higher composition, a little formed molten slag has covered the whole surface so that the analysis is impossible.

\section{Discussion}

\section{Evaporation of Tellurium from Molten Iron}

The results of Experiment I described in Section

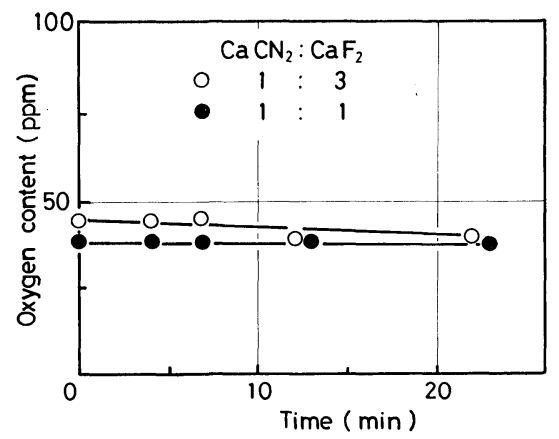

Fig. 9. Behavior of oxygen during the treatment of $\mathrm{Fe}-\mathrm{Te}$ melt with the $\mathrm{CaCN}_{2}-\mathrm{CaF}_{2}$ flux.

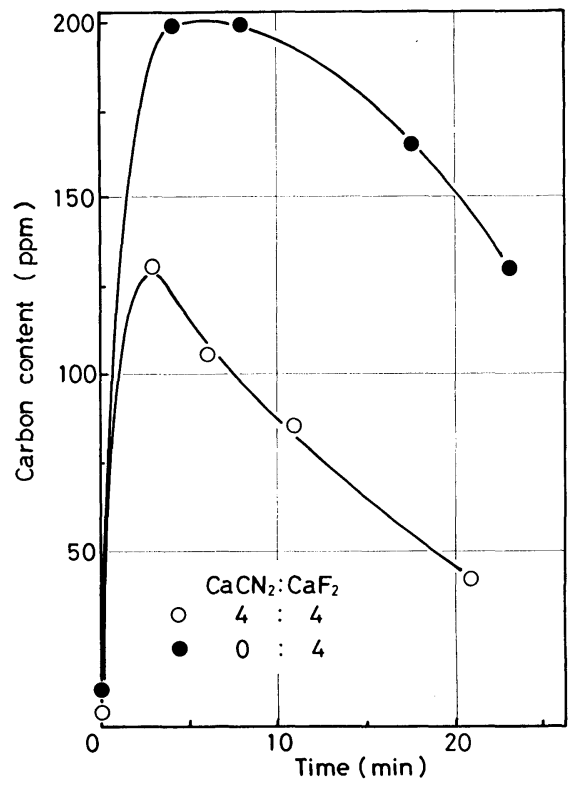

Fig. 10. Behavior of carbon during the treatment of $\mathrm{Fe}-$ Te melt with the $\mathrm{CaCN}_{2}-\mathrm{CaF}_{2}$ flux.

III. 1 was discussed through the kinetics on the evaporation of alloying element dissolved in molten iron. From the reported references concerned, ${ }^{5-13}$ ) the following equation

$$
\ln \frac{\left[\% \mathrm{Te}_{t}\right.}{[\% \mathrm{Te}]_{t=0}}=-k \frac{F}{V} t
$$

has been able to be extracted for the kinetics in spite of differences in the mechanism and the rate-controlling step, where $k$ is the total or the apparent mass transfer coefficient, $F$ the surface area for evaporation, $V$ the volume of molten iron and $t$ the time. Thus, a relationship was examined with graphing between the time and the concentration ratio in the left hand side term of Eq. (2). As shown in Fig. 11, the present results satisfy a good linear relation with a constant gradient. The mass transfer coefficients estimated from the slopes, are $2.10 \times 10^{-3} \mathrm{~cm} \cdot \mathrm{sec}^{-1}$ for the magnesia crucibles and $2.15 \times 10^{-3} \mathrm{~cm} \cdot \mathrm{sec}^{-1}$ for the alumina ones. Both the coefficients are remarkably coincident with each other, in spite of some differences in the shapes etc. No more details can be discussed, except that the thickness of the boundary layer is approved to be on the order of $10^{-2} \mathrm{~cm}$ estimated 


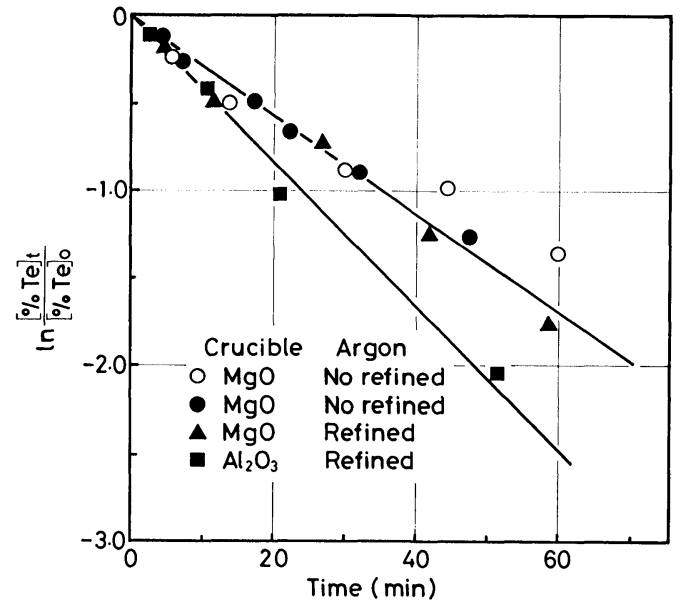

Fig. 11. Kinetic discussion on the vaporization of tellurium after Fig. 1.

through the boundary-layer theory of stationary diffusion in molten iron side.

\section{Discussion on the $\mathrm{CaF}_{2}-\mathrm{CaCN}_{2}$ Composite Flux}

Since there have been no studies on the elimination of tellurium out of molten iron, the reaction can be discussed only by reference to the desulfurization reaction in ESR with high $\mathrm{CaF}_{2}$ composition. The desulfurization in ESR process has been postulated to proceed through the evaporation of the formed fluoride, but has got a denial with the thermodynamical estimation and the experimental investigations carried out under oxidizing and neutral atmospheres. ${ }^{14)}$ On the other hand, Hawkins et al. ${ }^{15)}$ have reported that $\mathrm{CaS}$ is soluble in $\mathrm{CaF}_{2}$ within a solubility limit of $\mathrm{rd}$. 0.25 in molar fraction at $1550^{\circ} \mathrm{C}$, which has not been found in the X-ray investigations. ${ }^{\mathbf{1 6}, 17}$ ) As for the elimination reaction of tellurium, hence, there can be now a mere supposition that the formed tellurium compound probably dissolves in $\mathrm{CaF}_{2}$. No further details can be available.

As described in Figs. 6 and 7 in Section III. 3.1, the elimination of tellurium is dependent upon the composition of the $\mathrm{CaF}_{2}-\mathrm{CaCN}_{2}$ composite flux. The composite flux eliminates more tellurium out of molten iron than pure $\mathrm{CaF}_{2}$, and the best flux has a mixing ratio of about $1: 1$. The reason has been discussed as below.

Mitchell18) has considered through his study on the phase diagram of $\mathrm{CaF}_{2}-\mathrm{CaC}_{2}$ system that the reaction $\left(\mathrm{CaC}_{2}\right)$ in $\mathrm{CaF}_{2} \rightarrow(\mathrm{Ca})$ in $\mathrm{CaF}_{2}+[\mathrm{C}]$ in $\mathrm{Fe}$-alloy occurs in contact with molten ferroalloy. Nakamura et al. ${ }^{19)}$ also have reported the dephosphorization mechanism in $\mathrm{Fe}-\mathrm{Cr}-\mathrm{C}$ alloys on the basis of the above reaction. Moreover, the temporary increases in the carbon content have been observed in molten iron just after the addition of the composite flux as shown in Section III. 3.2. These concepts lead us to a mechanism that the composite flux seems to decompose as

$\mathrm{CaF}_{2}-\mathrm{CaCN}_{2}$ composite flux

$\longrightarrow(\mathrm{Ca})$ in $\mathrm{CaF}_{2}+[\mathrm{N}, \mathrm{G}]$ in $\mathrm{Fe}$
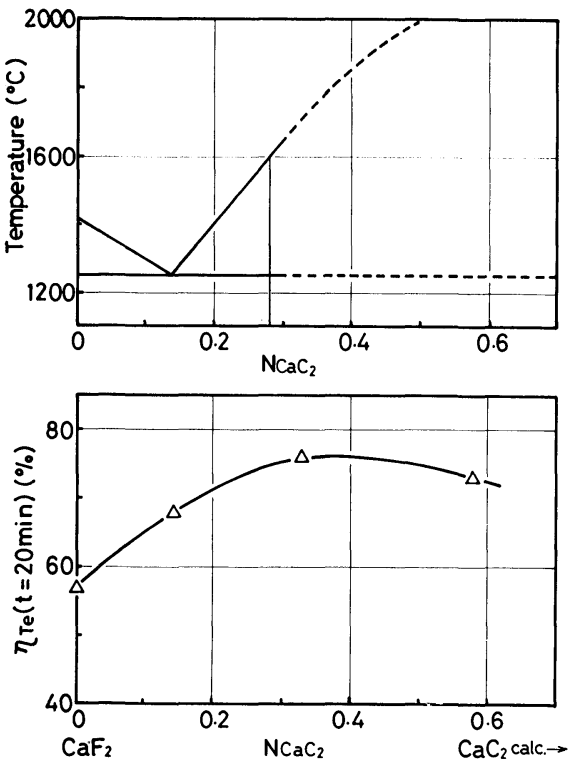

Fig. 12. Discussion on the optimum composition of $\mathrm{CaF}_{2}-$ $\mathrm{CaCN}_{2}$ flux.

in contact with molten iron even in the present case, and then the metallic calcium may dissolve in $\mathrm{CaF}_{2}$ melt to accelerate the elimination of tellurium. Although there has been yet no particulars, such as the decomposition degree of $\mathrm{CaCN}_{2}$ in the composite flux etc., the flux composition has been now altered into the expression for a binary $\mathrm{CaF}_{2}-\mathrm{CaC}_{2}$ system, on the assumption that the total amount of $\mathrm{CaCN}_{2}$ mixed decomposes perfectly into $\mathrm{CaC}_{2}$. The relation between the modified flux composition and the removability of tellurium was referred to the binary phase diagram of $\mathrm{CaF}_{2}-\mathrm{CaC}_{2}$ system figured by above mentioned Mitchell, as shown in Fig. 12. The solubility of $\mathrm{CaC}_{2}$ in $\mathrm{CaF}_{2}$ is about 0.28 in molar fraction at $1600^{\circ} \mathrm{C}$ according to the diagram. About 0.33 is the molar fraction calculated for the composite flux with the maximum removability of tellurium in the present study. Both the fractions are fairy good coincidental with each other. The excess amount of the component $\mathrm{CaCN}_{2}$ in the composite flux beyond the optimum composition forms the solid slag which seems to reduce the elimination of tellurium. The formation of the solid slag has been able to be confirmed by the observation of the formed slag shown in Section III. 3.3.

\section{Summary}

Since the co-existence of a small amount of tellurium seems to improve the practical deoxidation of steel with aluminum, the application can be expected in order to produce inexpensively fine steel. For this purpose, the present experimental examination was carried out to eliminate the residual tellurium out of steel under the conditions imagined as the subsequent treatment. Three kinds of experiments led to the following conclusions:

(1) Ar stream can fast rid molten iron of tellurium. $40 \sim 50 \%$ of tellurium was taken away for $20 \mathrm{~min}$ under the present experimental conditions. The rate satisfies the general kinetic equation for the 
evaporation of alloying elements.

(2) Rare earth metal is the most suitable substance to be added for the present aim, i.e., the elimination of tellurium at the low oxygen potential.

(3) On account of the combined actions of $\mathrm{CaF}_{2}$ purging the melt of tellurium and $\mathrm{CaCN}_{2}$ keeping it at low oxygen potential, intensive examination was carried out with the composite flux of the mixture, instead of the expensive REM. The mixture is applicable, especially one with a composition ratio of $1: 1$ which has succeeded in reducing the residual concentration of tellurium to rd. $20 \mathrm{ppm}$ (about 90\% reduction of tellurium) during 20 min treatment with little change in the concentrations of oxygen, carbon and nitrogen in the melt.

\section{REFERENCES}

1) T. Horigome, K. Shinmyo, T. Sato and M. Wakabayashi: Tetsu-to-Hagané, 59 (1973), 816.

2) T. Mukai and J. F. Elliott: JSPS, No. 19-9972, (1974).

3) S. Sawa, S. Shibuya and M. Ikeda: Japan Speciality Steel Technical Review, 11 (1976), 1.
4) K. Ogino, K. Noshiro and O. Yamase: Tetsu-to-Hagané, 62 (1976), S465 and 65 (1979), S12.

5) R. Higbie: Trans. A.I.Ch.E., 31 (1935), 365.

6) P. V. Danckwerts: Indust. Eng. Chem., 43 (1951), 1460.

7) L. V. Bogdandy, R. Schmolke and I. N. Stranski: $Z$. Elektrochem., 63 (1959), 758.

8) W. A. Fischer: Arch. Eisenhüttenw., 31 (1960), 1.

9) E. S. Machlin: Trans. Met. Soc. AIME, 218 (1960), 314.

10) H. Schenck and H.+H. Domalski: Arch. Eisenhüttenw., 32 (1961), 753.

11) H. Knüppel and F. Oeters: Arch. Eisenhüttenw., 33 (1962), 729.

12) R. G. Ward: JISI, 201, (1963), 11.

13) K. Ito and K. Sano: Tetsu-to-Hagané, 50 (1964), 1161.

14) H. Miska and M. Wahlster: Arch. Eisenhüttenw., 44 (1973), 81.

15) R.J. Hawkins, S. G. Meherali and M. W. Davies: JISI, 209 (1971), 646.

16) V. F. Skazin, O. D. Moldavskij, A. Ju. Poljakov and A. M. Samarin: Izv. Akad. Nauk SSSR, Metally, (1966), No. 2, 9.

17) B. M. Nikitin, T. I. Litwinova, and T. F. Rajčenko: $I z v$. Akad. Nauk SSSR, Metally, (1966), No. 6, 31.

18) A. Mitchell: Trans. Met. Soc. AIME, 242 (1968), 2507.

19) Y. Nakamura, K. Harashima and M. Ito: Tetsu-to-Hagané, 63 (1977), 2287. 